\title{
Collaborative research in contexts of inequality: the role of social reflexivity
}

Brenda Leibowitz, Vivienne Bozalek, Jean Farmer, James Garraway, Nicoline Herman, Jeff Jawitz, Wendy McMillan, Gita Mistri, Clever Ndebele, Vuyisile Nkonki, Lynn Quinn, Susan van Schalkwyk, Jo-Anne Vorster and Chris Winberg

\begin{abstract}
This article reports on the role and value of social reflexivity in collaborative research in contexts of extreme inequality. Social reflexivity mediates the enablements and constraints generated by the internal and external contextual conditions impinging on the research collaboration. It fosters the ability of participants in a collaborative project to align their interests and collectively extend their agency towards a common purpose. It influences the productivity and quality of learning outcomes of the research collaboration. The article is written by fourteen members of a larger research team, which comprised 18 individuals working within the academic development environment in eight South African universities. The overarching research project investigated the participation of academics in professional development activities, and how contextual, i.e. structural and cultural, and agential conditions, influence this participation. For this sub-study on the experience of the collaboration by fourteen of the researchers, we wrote reflective pieces on our own experience of participating in the project towards the end of the third year of its duration. We discuss the structural and cultural conditions external to and internal to the project, and how the social reflexivity of the participants mediated these conditions. We conclude with the observation that policy injunctions and support from funding agencies for collaborative research, as well as support from participants' home institutions are necessary for the flourishing of collaborative research, but that the commitment by individual participants to participate, learn and share, is also necessary.
\end{abstract}

\section{Introduction}

As a group of researchers and authors of this article, we use our experience of collaborating on a large, national multi-site education research project to reflect on the conditions that influence the outcome of collaborative research. We draw attention to how working across geographical distances amidst contextual conditions of educational, social and institutional privilege and inequality, may influence the collaboration, and to how what has been termed 'social reflexivity' (Donati, 2010) or 'corporate agency' (Archer, 2000) may mediate these influences. We discuss the benefits as well as difficulties associated with collaborative educational research, how social reflexivity and corporate agency are discussed in the literature, before presenting the educational research setting in which an overarching educational research project and a sub-study on collaboration 
occurred. Our collaboration took place in South Africa, but we believe our experiences are relevant in any setting that involves social as well as geographical distance and inequality.

\section{Collaborative educational research}

Claims for the value of collaborative research on higher education are increasingly made in the literature on teaching and learning in higher education. Collaborative research is said to enhance the quality of the research outcomes (Kezar, 2005; Kahn, Petichakis, and Walsh, 2012) and the potential for the professional learning of the collaborators (Leibowitz, Bozalek, Carolissen, Nicholls, Rohleder and Swartz, 2012; Cox 2006; Walker 2001; Smith, MacKenzie, and Meyers 2014).

It is acknowledged that collaborative research is complex (Kahn, Petichakis, and Walsh 2012; Sullivan, Stoddard, and Kalishman 2010) and that numerous challenges are posed, which are likely to increase with the size or diversity of the group (Brew et al. 2012), its disciplinary composition (Bossio et al. 2014) and other intersubjective features such as academic expertise and identity (Leibowitz, Ndebele, and Winberg 2014). According to Kezar (2005), 50\% of collaborations in higher education fail. Studies on collaborative research in or about higher education thus advocate close attention to the structure and working of the collaborative group, in order to enhance its outcomes and reduce risk (Brew et al. 2012). Kahn, Goodhew, Murphy and Walsh (2013) highlight the importance for effective collaboration of interaction internal to the collaboration, such as structural and material conditions in the surrounding work contexts. Brew, Boud, Lucas and Crawford (2012, p. 94) have likewise drawn attention to the significance of systemic structural and cultural conditions external or prior to the collaboration. They highlight 'the institutional context and the role we occupy ... and personal histories, positions and career trajectories'. They draw on theorising about structure and culture in order to suggest that individuals within a team may mediate these internal and external structural and cultural influences. If this mediation is effective, it enables the emergence of collaborative behaviour, or 'corporate agency', which is defined as the group working towards a common pursuit (Kahn, Petichakis and Walsh 2012). These studies suggest a promising avenue for investigating the workings of collaborative research teams, which allows for a more overt focus on the systemic social and contextual conditions, and how the team members may or may not mediate these conditions.

Collaborative research can imply either loose working together, where creativity and understanding is facilitated, such as within the humanities and social sciences, or tight working together on common questions and methods, typically in the natural sciences (Lewis, Ross and Holden 2012). In South Africa, where the National Research Foundation (NRF) may fund a group to work together and postgraduate students to embark on interwoven or parallel studies, one can find a combination of these two approaches. In many cases collaborative research involves individuals working across disciplines, institutions or geographic locations. In our study, individuals are working within one field, i.e. academic development, but across institutions and within a diversity of social and geographic locations in one country. Collaborative research projects that are facilitative of research outcomes and individual participation and learning have been described in earlier work as communities of practice, after the work of Wenger (1998). A key element of communities of practice, is the participation of experts alongside non- 
experts. The latter learn from the practice of the experts and gradually become more central to the collaboration. Christie et al (2007) use the term 'communities of enquiry' to refer to communities of practice that focus on enquiry or research. These communities draw on a diversity of perspectives to generate new knowledge. Both terms highlight the benefits for creativity and participant identity from participation. Collaborative groups however take time to generate shared norms and rules (Kezar 2005) and this process might require deliberate attention.

\section{Collaboration as corporate agency}

A contribution that Kahn, Petichakis and Walsh (2007) have made to the debates on collaborative research is to link the idea of a group working towards common goals to Margaret Archer's concept of 'corporate agency' (Archer 2000). They support the idea expressed by Archer (2000, p. 60) that the shift from individual agency to corporate agency requires deliberate attention. They stress the significance of corporate agency in shaping positive collaborative outcomes:

While Archer gives a central place to an individual's own reflexive deliberations in the way the agency of an individual is realised, (Archer 2007), social interaction is required for a group to identify, prioritise and act on mutual concerns (Kahn, Petichakis and Walsh 2007, p. 5).

They point to other contextual features that retard or impede collaborative work, including structural and material or natural features in the individuals' work environment, the roles that individuals play within the collaboration and, citing Putnam (2000), 'forms of social capital' of which 'trust' is the most essential. Thus key to an analysis of the emergence of a positive collaborative outcome are contextual features external to and internal to the collaboration, features which are structural and cultural, and features related to how individuals interact with each other. The external and internal structural and cultural features may impinge upon the growth of a collaborative modus operandi. Central to an Archerian view is that this is mediated by individuals' agency, key elements of which are their reflexivity, their values and commitments (Archer 2007). Donati develops Archer's work on reflexivity to suggest that in the modern era there is a strong trend towards 'social reflexivity', referring to how people interact with each other, consciously, to engender more collaborative approaches. He describes 'social reflexivity' as an 'operative capability creating new social forms with self-steering competences' (Donati 2010, p. 145). In other words, there is a cyclical process of change in which individuals consciously create networks or structures in which they can share intellectual goods. Thus individual agency and corporate agency are both central to an understanding of how collaborative working teams emerge - as are the structural and cultural conditions internal and external to the collaboration, which individual and corporate agency then mediate.

\section{Research setting}

The setting of this collaboration is South African higher education, where there are great levels of inequality between institutions due to their differing geographic locations, levels of resourcing, cultural and political histories, and current demographic make-up. Members of our team have provided descriptions of this setting and how it influences 
teaching and learning and academic development more broadly (Leibowitz, Bozalek, Winberg and van Schalkwyk 2015). Inequality pertains not only to institutions, but also to individuals who learn and teach at these institutions. This inequality is a logical outcome in a country with one of the highest degrees of wealth disparity in the world, and where there was previously a history of legislated inequality on the basis of both race and class. These disparities also affect the conditions and biographies of those who practice as academic developers.

The field of academic development is by no means homogeneous. There are strong trends of job insecurity, lack of academic identity and marginalisation of academic developers in many countries and institutions. Trowler (2004) maintains that academic development units all over the world face problems including mistrust and marginalisation. Challis, Holt and Palmer (2009) write about the widespread restructuring of academic development centres in Australia. Green and Little (2013) and Manathunga (2007) refer to the peripheral position of academic developers as 'migrants'. In South Africa the varied status and support for academic developers is aggravated by the social and educational institutional disparities referred to above. These inequalities have an influence on the research that is conducted on academic development: on its quality and quantity, and on the extent to which the field is dominated by researchers from more elite institutions. Boughey and Niven (2012, p. 652) point out that research in the field of academic development in South Africa is 'patchy' and it tends 'to be centred in historically privileged spaces'

This is the setting in which a group of 18 academic developers from eight universities came together in response to a call from the South African National Research Foundation (NRF) for applications for collaborative education research, involving a minimum of three universities, of which at least one had to be from a rural location. The result of the grant applications were a three-year collaborative research project and a three-year extension thereof.

The study investigated the professional development of academic staff in their roles as university teachers. All 18 project participants were involved in the professional development of university teachers. The focus of the collaboration was to build knowledge around why academics choose to participate in professional development opportunities as well as knowledge about the enabling and constraining conditions at their institutions for continuous professional development. The research design was based on a framework focusing on the interplay of structure, culture and agency, which was derived loosely from the work of social realist Margaret Archer (1995, 1996, 2000, 2007). The 18 participants were of varying levels of seniority, and included a dean of teaching and learning, directors of centres, centre- and faculty-based academic development practitioners, and $\mathrm{PhD}$ and Masters' candidates. While most were employed in academic posts, some occupied positions designated as administrative, where little provision was made for time to conduct research. A short description of the researchers who elected to become writers of this paper is provided in the appendix. All participants had had experience of conducting research using social and educational theories. Some had completed PhDs using social realism, while for others, this framework was completely new. Some were seasoned 
researchers who had published extensively and had co-ordinated large-scale NRF projects themselves. A number were new to large-scale research collaboration.

Since the participants came from universities across South Africa, face-to-face communication was limited. Discussions were facilitated through a variety of electronic media, including e-mail, Skype, a website, a project blog, and Dropbox. Face-to-face twoor three-day meetings were scheduled twice yearly, for planning, collaborative working sessions and writing. For participants from universities in rural areas, face-to-face meetings meant a significant amount of travelling by both road and air.

The team decided to research their experiences at the end of the first year of the project, and three of the project members wrote this up. This first study focused on the benefits of the collaboration and some of the challenges, especially those pertaining to members' academic identities (see Leibowitz, Ndebele and Winberg 2014). At the end of the third year, 14 members of the team decided to contribute to a paper based on our perceptions of the collaboration. We were curious to experience the process of co-authoring a paper, and we wished to challenge the trend in the arts and humanities for papers written by one, two or three writers. We also wished to challenge a prejudice in many of our own institutions against multiple authorship as this is seen as submerging the original contribution and voice of the single author, who would have to share the incentive funding gained for publishing. This is the norm in most South African institutions. Our first article on collaboration was informed by the literature on reflection and academic identity. For this second article we thought it would be interesting to test the conceptual framework we had adopted for the main study on professional development, namely the interplay between structure, culture and agency, informed by the work of Margaret Archer. A final motivation was that by writing together, we would cement our collaboration and sense of accountability (Brew et al., 2012). We hoped we would learn from the challenging experience of writing together, in which 'writing up' is seen as a key 'process of meaning making' (Lingard et al. 2007, p. 512). In our analysis we were looking for clues to answer the following questions:

1. Could this research process be described as 'collaborative'?

2. What are the structural and cultural features that impede and facilitate collaborative research in South Africa as a context of extreme inequality (and are these features the same as those discussed in other studies)?

3. What role has individual and group agency played in generating the success of our research collaboration?

\section{Research design}

This was a participatory study in that we were all working within the field of academic development and were researching the field. We defined the purpose and constructed key elements of the research design for the larger study on professional development together.

For this study on collaborative research, we have adopted what might be referred to as a 'group reflection' (Heron 1985; McTaggart 1991). 


\section{Data generation}

We used a similar data collection technique to our previous reflective exercise after the first year of the team's existence (see Leibowitz, Ndebele and Winberg 2014) namely the collection of loosely structured reflective pieces by each research team member. After the team decided to document their reflections of the process in the third year of the research project, the team leader devised an electronic questionnaire with four open-ended questions to facilitate a reflective process.

1. What have been the outputs and outcome of your participation for you thus far?

2. What have the challenges been for you in achieving these or any outputs or outcomes?

3. What has facilitated your participation? (In your work context/institution? By the project itself? By you?)

4. What has hindered your participation? (In your context/institution? By the workings of the project itself? By you?)

These reflective questions were discussed at a face-to-face meeting and then e-mailed to all team members to be answered individually. There was an agreement that all responses would be made available to everyone and that members could decide to remain anonymous. No one opted for anonymity, an indication of the trust that existed within the group. The data from the reflections constituted team members' experiences of the collaboration, which according to a critical realist view, was data from the realm of the 'empirical' as it depends on one's observation and experience (Sayer 1998, p. 134). These are data about individual perceptions of reality and the inter-relationships that ensue between individuals, groups, events and contexts (Maxwell 2012). Archer (2010) writes that when investigating reflexivity first-person accounts should be utilised, as agents are active, and strong evaluators, conscious of their emotions and motives. The collection of statistics and publically available data about each of the eight institutions where the writers worked (collected for the larger study) was utilised. This contextual data informed our analysis of the comments made by individual team members.

\section{The process of analysis and write-up}

We sought to understand the structural and cultural conditions in the institutions where we worked, as well as the conditions within the project itself, that presented as potential constraints or enablements, depending on the way that as individuals in the group, we responded to them. This approach followed on from the way that reflections were analysed by two important contributions on collaboration using Archer's (1995) morphogenetic approach to change: those of both Kahn, Petichakis and Walsh (2007) and of Brew, Boud, Lukas and Crawford (2012). Some of us analysed the reflections in pairs according to the themes of structure, culture and agency, and project outcome, whilst others, in pairs, wrote up sections for the paper, such as the introduction, literature review, methodology or research setting. Each individual or pair submitted their sections to the project leader, who collated them. A draft was circulated within the group and contributed to by participants in a cyclical process of reading, writing and improvement during two face-to-face meetings, via email correspondence and during a meeting via Skype. Amongst the issues we debated, was whether we could find a coherent argument, and whether we had anything original to contribute. A conference presentation on the 
collaboration was made by three team members. Various iterations of the manuscript were prepared. A critical friend provided additional comment. The fact that the script had to be tidied in successive versions by at most two or three individuals, despite at each stage obtaining comment from each participant, bears testimony to the difficulty of crafting a large group research paper - certainly in the social sciences.

\section{Outcome of the collaboration}

We begin by describing the outcome of the collaboration, before going on to describe the conditions and deliberations that could, in our view, account for this. Our study is based on the notion that corporate agency or social reflexivity enhances the outcome of collaborative research. In order to assert that our study has had a productive collaboration, we thus needed a measure by which to describe what a successful collaboration may be. We posited collaborative research on academic development as successful in terms of three related dimensions: first, the generation of research outputs in relation to quantity (for example number of articles) and quality (for example whether new or useful knowledge has been generated); second, whether the research team members learnt, either about research methods or about academic development; and third, the extent to which the data gathered had catalytic impact on participants in their own settings. Catalytic impact (Lather 1986) would imply impact on the thinking of the participants, who in this case are the researchers, as well as on the thinking of colleagues in their immediate work contexts.

In terms of the delineation of successful outcomes, the collaboration could be described as 'reasonably successful'. The team membership has remained relatively stable with a core of 14 individuals remaining for $4^{1 / 2}$ years. Project outputs include: 16 journal articles; 25 conference presentations and two conference panels; one full day national colloquium arranged by the team; one full page article in a weekly newspaper; one special issue of a South African journal and three book chapters in process; three PhD studies in process; a sub-project linking up with an international research project; and two successful funding proposals. With regard to research impact, it would be fair to say that the project has initiated an important conversation about professional development and context in the South African academic development field. However at this stage, the project has not had significant impact via its findings or recommendations, since these are currently being processed. At several, but not all participating institutions, the institutional case study reports have been tabled at institutional seminars or teaching and learning committees.

With regard to growth in understanding, the majority of us recorded significant research growth. Some learned about research techniques, some about the critical realist theory:

The various workshops and learning opportunities have enabled me to understand the concepts (or at least some of them!) and take on the realist discourse - ...we still debate about whether something is structural or cultural - and we correct each other - and that's part of the learning. Last night it was pointed out that I was using 'agency' incorrectly. So I got stuck into Archer again to figure it out. So for me the learning has been HUGE! (14i) 
We learnt about how professional development is conducted at other universities in the region, which is significant in that one of the aims of the project was to advance professional development at our own institutions:

The project has given me the opportunity to meet face to face with colleagues from a range of other higher education institutions in South Africa, and to gain access to how professional development is perceived in these different contexts. (1)

The project has served as an important benchmarking tool as I establish a new academic development centre at my university. Through sharing with colleagues, going through institutional reports and data collected from fieldwork, I have been able to glean useful information on how I can develop a staff development agenda for my university. (9)

It is significant that team members maintained that we learned via workshops and formal inputs, as well as via participation, which would be typical of a community of practice (Wenger, 1998). We learnt from participating in the large group, subgroups, or via generating research outputs,

A major benefit for me has been in the area of writing for publication. Through a collaborative process with two seasoned researchers resulting in a publication in a highly rated higher education journal my confidence in publishing was boosted. Through learning from the process I have ... been able to publish three articles in peer-reviewed ... journals. (9)

In this section we have shared the kinds of benefits we have derived from the collaboration. In the next section we discuss the structural and cultural conditions external to and internal to the collaborative project, which appeared to hinder or facilitate the participation of the researchers.

\section{Contextual conditions}

\section{Structural conditions}

As project members we had different levels of flexibility and autonomy at work, which affected our participation. Similarly, while the project provided some basic resources, at our institutions we had varying degrees of access to additional resources. One of our participants, from a historically advantaged urban university, had resources he could draw on from his own institution to enhance his participation and contribution to this project:

I have money (from another project) for a research assistant that I am using to keep work on the data ticking over - that has been some help. (5)

A key institutional enabling feature identified was the support of managers, particularly those who encouraged us as academic developers to do research. Several managers were reported as taking a keen interest in the project, acknowledging its importance, and enabling participants to attend project meetings and engage in research activities. 
A significant feature impacting on participation was some of our workloads, as well as commitments in our personal lives (as alluded to by Kahn, Petichakis and Walsh 2012):

Due to workload and time issues, most of us could only really apply our minds to the project when deadlines came nearer and requests for information were repeatedly sent out. I struggled finding enough time and head space for my $\mathrm{PhD}$ and the project together with a full plate at work and trying to survive as a person as well. (4)

Time constraints were exacerbated by capacity shortages, which from the broader analysis of contextual influences, appeared to be most prominent at rural, historically disadvantaged universities:

... the inability to attract suitably qualified personnel who have the knowledge and experience of academic development work also meant that the centre had to operate with skeleton staff, the few appointees need hand-holding. This meant that the time had to be divided over a number of the centre activities thus leaving me with minimal time devoted to the project's activities... (10)

With regard to the project itself, the main structural challenge was the condition of this being a large, geographically distributed group. The size of the group made it unwieldy and the geographic spread of the project resulted in infrequent meetings and travel fatigue:

The main challenge I have faced has been travelling long distances to the meeting places in Cape Town. Travelling has been very exhausting and I would have problems of working well on the first days of meetings due to exhaustion. (9)

A further challenge pertaining to the project itself was that funding received from the NRF was significantly less than the original amount requested. This meant that some of the resources initially requested, such as a project coordinator, administrative assistants, interviewers and transcribers, were either removed from the budget or given reduced funding. A feature that many mentioned, that was primarily caused by the lack of sufficient funds, was having to work in a piecemeal fashion: participants could only give the project attention 'in bursts' (6). This meant that some of us struggled to find 'enough time and head space' (4) to fully engage with the project. For the project leader this involved: ' ... nagging ... nagging ...' (6).

An enabling feature internal to the project was that within the large, unwieldy group structure, smaller working teams encouraged participation:

$[\mathrm{XXX}]$ and I have met to write an article about our medical education experiences. (7)

As the quotation above suggests, many of us found the structural enablements of the 'subprojects' (5) very fruitful. In fact other than this article, most of the articles were produced by small teams of between two and four individuals. Kahn, Petichakis, and Walsh (2012) explain that while there are advantages to be gained from large collaborations across multiple sites, work is usually achieved in sub-sets of the larger group. In their reflective 
study on research collaboration, Brew et al. (2012) point out the importance of 'personal projects' that reside within collective activities, for it is these that enable development of research identities. This points to the value of the loose version of collaboration as described by Lewis, Ross and Holden (2012), where individual or smaller projects are undertaken in parallel. However in our experience the tighter collaboration also led to learning, for example when we undertook a combined approach to coding data, and trained ourselves together on the method.

\section{Cultural conditions}

For the purpose of this paper 'culture' refers to the norms, values and ideas that reside within the project as well as the cultures of the home institutions. Culture in any context can either be accommodating or hostile which in turn can influence the motivation of the individual (Leibowitz et al. 2012b). People come into a context with innumerable interrelated theories, beliefs and ideas which had developed prior to it and. ... exert a conditional influence on it' (Archer 1996, xxi). The disparate provisioning of institutional research support structures in the advantaged and less advantaged institutions, and inconsistent attitude towards the status and role of academic development practitioners (Boughey and Niven 2012) was mentioned earlier in this article. This varied level of support affected the participants from historically disadvantaged institutions more severely, bringing the value of collaboration on the project into stark relief:

Coming from an academic institution where research and publishing by the academic developers has in the past not been emphasised, the need to reflect on, and share our practices through research and publications on our practices is made critical by my involvement in a study of national magnitude. (10)

A significant cultural resource that positioned team members differentially in relation to our ability to participate in the project was access to the theoretical framework underpinning the project. Those who came into the project with some knowledge of this theory inevitably felt more comfortable and were able to assume more 'expert' positions in relation to the theory:

I gathered from the earlier paper that some of the project members found the social realism/critical realism theoretical framework which was used for the project difficult and challenging. I suppose I was lucky to have come into the project with some of that theory. (11)

Those of us who enjoyed this theoretical mastery were from advantaged institutions, whilst those who did not, were both experienced and less experienced academic developers, from advantaged and disadvantaged institutions. Some found the lack of mastery of the theoretical framework to be a hindrance to participation, making statements like 'I was very resistant to social realism in the beginning' (14) and felt ourselves being positioned as novices.

One of the writers of this paper felt this difference in access to the theoretical framework could be attributed to an intersection of research seniority and institutional affiliation. She wrote in an early contribution to this paper: 
I am tentatively exploring the possibility of a discourse regarding the valuing of collaborative research that draws attention to the divide between HBU's (historically black universities) and novices [on the one side] and HWU's (historically white universities) and experienced participants [on the other side]. Members in the team from HBUs and PhD students [from both HBU and HWU institutions] make reference to 'growth and developments within the collaborative research process' ... Whereas members in the team from HWU's and experienced and established $\mathrm{AD}$ practitioners and researchers are more critical of the collaborative process whilst also appreciative of the collaboration in learning collaboratively about a new theoretical framework. (8)

There is a suggestion in comments like this one that access to dominant, powerful or current theory may serve as a fulcrum around which dynamics around power and privilege in collaborative research revolve. We have not given this matter substantial attention and this could be a valuable line of enquiry for our group in the future.

Given the way our varied contexts impinged on our participation in this research team, how did it occur that the project enabled people to learn from each other and to publish together? We would argue that this is an effect of individuals' agency, influencing their participation and willingness to learn, and of their deliberate support for the emergence of corporate agency or social reflexivity, as will be discussed in the next section.

\section{Individual and corporate agency}

Our reflective pieces illustrate how as individuals, we chose to remain involved in the collaboration, or even to become more involved over time. Our participation was strongly influenced by our commitments, concerns and investments in the project. Emphasizing the role of commitment and concern driving a mode of behaviour (Archer 2007) was the idea repeated by several of the team members that we all subscribed to similar values regarding the importance of higher education and of lecturers learning to teach: 'There is a sense that we can have an impact, and make a difference to staff development through this work. It feels important.' (14)

Many of us saw the project as a 'natural extension' (1) of our work, with the potential to contribute towards the advancement of academic development, both at our home institutions and within the larger national context. One participant had an interest in the strategic way in which the project could be used' (1) at her institution. Another noted the 'desire to keep in touch with national level and a commitment to my colleagues, especially those with whom I have worked more closely' (12). Generally, it was felt that the project had reinforced 'growing beliefs in the value of collaborative work across disciplines, faculties, higher education institutions, geographical locations, etc' (1).

Team members explained how we were motivated to participate by the sense that we would gain something of benefit to our professional practice:

Through sharing with colleagues, going through institutional reports and data collected from fieldwork, I have been able to glean useful information on how I can develop a staff development agenda for my university. (9) 
It is because I participate in research projects like this one that I am able to contribute to my institution in a considered, consistent, research- and theory-informed as well as hopefully constructive way. (14)

Kezar (2005) writes that collaborative groups take a while to consolidate norms and values. Despite common concerns and commitments, for some, participation was initially difficult. Especially amongst all the PhD students, there was a sense of hesitancy and reserve in the beginning:

... my own lack of knowledge about research and its processes caused me to feel unsure and sometimes even feeling totally stupid or ignorant which then kept me from participating or saying something. (4)

Each of these students became more comfortable and participative over time:

I do feel more confident in sharing my ideas compared to the beginning of joining the project. This has to do with the manner in which my ideas have been accepted by the larger group as well as my own reading and understanding of the literature. (2)

All three PhD students attributed their increasing sense of comfort, to a certain degree, to the collaborative ethos in the group:

My earlier reserve was attributable perhaps to my positioning myself in the project as an unseasoned $\mathrm{PhD}$ candidate, and influenced by childhood directives of 'listening rather than speaking in the company of the accomplished' ... I note happily, a change in this earlier reserve, with increased personal interaction with members in the team and developing a sense of ease enabling me to 'share my piece'. (8)

These comments suggest that a sense of corporate agency (Archer 2007) emerged, arising out of social interaction (Kahn et al. 2007) that was consciously constructed in order to generate 'operative capability creating new social forms with self-steering competences' (Donati 2010, p. 145). Three features common to the group that could have helped generate this degree of corporate agency are: the commitment and belief in the importance of academic development, belief in the value of collaborative research, as discussed above, and a conscious sense of sharing and collaboration, as described by a seasoned researcher on the project:

I think this, for me, has been one of the most astonishing characteristics of this group of colleagues - their spirit and willingness to share resources, intellectual property, and give generously of their time. I have really appreciated that - and found it unusual in the often ungenerous and competitive university environment. (7)

The existence of novices as well as experts who shared their knowledge is typical of communities of practice (Wenger 1998). It could be argued that this spirit of generosity and the appreciation thereof is evidence of the bridging capital referred to by Kahn, 
Petichakis, and Walsh (2012), and that this capital resides in those who have expertise to share, as well as those who are willing to take advantage of this.

The PhD students' observations about their participation and the support for their involvement attests to the manner in which corporate agency emerges out of social interaction where there is conscious attention to this interaction, leading to new and valuable forms of interaction and valuable outcomes, as suggested by Donati (2010).

\section{Conclusion}

In this article we have written about our experiences as researchers in the academic development field to shed light on the opportunities and joys, as well as challenges and threats that may be encountered in large group research collaboration. Many of the challenges and threats are more visible in settings of evident educational inequality, especially when interwoven with the stresses and strains generated by the instability and lack of academic identity that many academic developers experience. This does not imply that power issues and resource imbalances are unique to this setting. It is arguably the case, however, that where these inequalities are more stark, the need for collaboration, corporate agency or social reflexivity are more challenging to cultivate - yet more necessary, if not essential. Our collaboration took place in South Africa, but we believe our experiences are relevant in any setting that involves social as well as geographical distance and inequality.

Our reflections highlighted many of the structural and cultural features emanating from the institutional contexts in which the researchers worked and from the collaboration itself, that were discussed by Brew et al. (2012) and Kahn, Petichakis and Walsh (2012). In our case the structural inequalities relating to our post-apartheid reality and differently resourced institutions, aggravated by the status and work identity of academic developers at these institutions, was more apparent than in either of these two studies. We are aware of reflective writings about collaboration that do refer directly to power relations, for example the work of Griffien, Hamberg and Lundgren (2013) and Lingard et al. (2007), where the tensions and power differences were strongly influenced by differences in disciplinary allegiances, but have not found other studies in which institutional inequalities are as apparent as in our case.

Our experience of collaborative educational research lends support to the notion that structural and cultural conditions impinge on the work of a research team, and further, that they shape the 'action contexts' (Archer 2010, p.12). It also lends support to Archer's observation that 'agents are active' (Archer 2010, p.12), and thus, mediate these influences - both as individuals and as a group. This is indeed significant for educationists who seek to work towards positive educational outcomes, as it suggests that whilst individuals are not totally free from the constraints of their institutional contexts, they do have an ability to influence the outcomes of their projects. This also suggests that it is worthwhile to pay attention to how collaborative work is structured and supported, both by individuals working in teams, and by policy generating bodies and research support agencies. The modus operandi of collaborative educational research teams should not be left to chance. Donati (2012, p. 144) expresses the concern for reflexivity to become 'an operative capability creating new social forms with self-steering competences'. A 
deliberate cultivation of a sharing approach by both experienced and novice researchers is an important goal for collaborative research teams.

\section{Appendix: Co-writers' biographical information}

\begin{tabular}{|c|c|c|c|c|c|c|c|c|}
\hline \multicolumn{5}{|c|}{ Participant Biographical Information } & \multicolumn{4}{|c|}{ Description of Participant's Institution } \\
\hline No & Gender & Race & Position & $\begin{array}{l}\text { PhD } \\
\text { Student } \\
\text { on } \\
\text { Project }\end{array}$ & $\begin{array}{l}\text { Historical } \\
\text { legacy }\end{array}$ & Focus & Classification & $\begin{array}{l}\text { Urban } \\
\text { v. } \\
\text { Rural }\end{array}$ \\
\hline 1 & female & white & director & & disadvantaged & teaching & traditional & urban \\
\hline 2 & female & coloured & advisor & $\checkmark$ & advantaged & research & traditional & urban \\
\hline 3 & male & White & $\begin{array}{l}\text { ass. } \\
\text { prof }\end{array}$ & & $\begin{array}{l}\text { merged: } \\
\text { disadvantaged } \\
\text { and } \\
\text { advantaged }\end{array}$ & teaching & $\begin{array}{l}\text { university of } \\
\text { technology }\end{array}$ & urban \\
\hline 4 & female & white & $\begin{array}{l}\text { senior } \\
\text { advisor }\end{array}$ & $\checkmark$ & advantaged & research & traditional & urban \\
\hline 5 & male & white & $\begin{array}{l}\text { assoc. } \\
\text { prof }\end{array}$ & & advantaged & research & traditional & urban \\
\hline 6 & female & white & director & & advantaged & research & traditional & urban \\
\hline 7 & female & white & $\begin{array}{l}\text { assoc. } \\
\text { prof }\end{array}$ & & disadvantaged & teaching & traditional & urban \\
\hline 8 & female & Indian & advisor & $\checkmark$ & $\begin{array}{l}\text { merged: } \\
\text { disadvantaged } \\
\text { and } \\
\text { advantaged }\end{array}$ & teaching & $\begin{array}{l}\text { university of } \\
\text { technology }\end{array}$ & urban \\
\hline 9 & male & african & director & & disadvantaged & teaching & traditional & rural \\
\hline 10 & male & african & advisor & & $\begin{array}{l}\text { merged: } \\
\text { disadvantaged }\end{array}$ & teaching & traditional & rural \\
\hline 11 & female & white & director & & advantaged & research & traditional & rural \\
\hline 12 & female & white & $\begin{array}{l}\text { deputy } \\
\text { director }\end{array}$ & & advantaged & research & traditional & urban \\
\hline 13 & female & coloured & $\begin{array}{l}\text { senior } \\
\text { lecturer }\end{array}$ & & advantaged & research & traditional & rural \\
\hline 14 & female & white & director & & $\begin{array}{l}\text { merged: } \\
\text { disadvantaged } \\
\text { and } \\
\text { advantaged }\end{array}$ & teaching & $\begin{array}{l}\text { university of } \\
\text { technology }\end{array}$ & urban \\
\hline
\end{tabular}




\section{References}

Archer, M. (1995). Realist social theory: The morphogenetic approach. Cambridge: Cambridge University Press.

Archer, M.S. (1996). Culture and agency: The place of culture in social theory. Cambridge: Cambridge University Press.

Archer, M.S. (2000). Being human: The problem of agency. Cambridge: Cambridge University Press.

Archer, M.S. (2007). Making our way through the world: Human reflexivity and social mobility. Cambridge: Cambridge University Press.

Archer, M. (2010). Introduction to M. Archer (Ed.), Conversations about reflexivity. London: Routledge.

Bossio, D., Loch, B., Schier, M. \& Mazzolini. A. (2014). A roadmap for forming successful interdisciplinary education research collaborations: A reflective approach. Higher Education Research \& Development, 33(2), 198 - 211.

Heron, J. (1985). The role of reflection in comparative enquiry. In: D. Boud, R. Keogh and D. Walker (Eds), Reflection: Turning experience into learning. Milton Park: RoutledgeFalmer.

Boughey, C. \& Niven, P. (2012). The emergence of research in the South African Academic Development movement. Higher Education Research \& Development, 31(5), 641653.

Brew, A., Boud, D., Lucas, L. \& and Crawford, K. (2012). Reflexive deliberation in international research collaboration: Minimising risk and maximising opportunity. Higher Education, 66(1), 93-104.

Challis, D., Holt, C.D. \& Palmer, S. (2009). Teaching and learning centres: Towards maturation. Higher education research \& development, 28(4), 371-383.

Christie, D., Cassidy, C., Skinner, D., Coutts, N., Sinclair, C., Rimpilainen, S. \& Wilson, A. 2007. Building collaborative communities of enquiry in educational research. Educational Research and Evaluation, 13(3), 263-278.

Cox, M. (2006). Phases in the development of a change model: communities of practice as change agents in higher education. In L. Hunt, A. Bromage, \& B. Tomkinson (Eds.), The realities of change in higher education: Interventions to promote learning and teaching. London: Routledge.

Donati, P. (2010). Reflexivity after modernity. In: M. Archer (Ed.), Conversations about reflexivity (pp. 144-164). Abingdon: Routledge.

Green, D. \& Little, D. (2013). Academic development on the margins. Studies in Higher Education, 38(4), 523-537.

Griffin, G., Hamberg, K. and Lundgren, B. (2013). The social politics of research collaboration. London: Routledge.

Kahn, P., Petichakis, C. \&Walsh, L. (2012). Developing the capacity of researchers for collaborative working. International Journal of Researcher Development, 3(1): 49-63.

Kezar, A. (2005). Redesigning for collaboration within higher education institutions: An exploration into the developmental process. Research in Higher Education, 46(7), $831-60$.

Lather, P. (1986). Issues of validity in openly ideological research: Between a rock and a soft place. Interchange, 17(4), $63-84$. 
Leibowitz, B., Bozalek, V., Carolissen, R., Nicholls, L., Rohleder, P. \& Swartz, L. (2012a) Educating the educators: Creating a powerful learning environment. In: B. Leibowitz, L. Swartz, V. Bozalek, R. Carollissen, L. Nicholls and P. Rohleder (Eds.), Community, self and identity: educating South African university students for citizenship (pp.117 - 129). Cape Town: HSRC Press.

Leibowitz, B. Bozalek, V. Winberg, C. and van Schalkwyk, S. (2015) Institutional context matters: The professional development of academics as teachers in South African Higher Education. Higher Education, 69 (2), 315 - 330.

Leibowitz, B. Ndebele, C. and Winberg, C. (2014) The role of academic identity in collaborative research. Studies in Higher Education, 39 (7), 1256 - 1269.

Lewis, J.M., Ross, S. \& Holden, T. (2012). The how and why of academic collaboration: Disciplinary differences and policy implications. Higher Education, 64, 693-708.

Lingard, L., Schryer, C., Spafford, M. \& Campbell, L. (2007). Negotiating the politics of identity in an interdisciplinary research team. Qualitative Research, 7(4), 501-519.

Manathunga, C. (2007). "Unhomely" academic developer identities: More post - colonial explorations, International Journal of Academic Development, 12(1), 25 - 34.

Maxwell, J. (2012). A realist approach for qualitative research. Thousand Oaks: Sage.

McTaggart, R. (1991). Principles for participatory action research. Adult Education Quarterly, 41(3), 168-187.

Sayer, A. (1998). Abstraction: A realist interpretation. In Archer, M., Bhaskar, R., Collier, A., Lawson, T. \& Norrie, A. (Eds.), Critical realism: Essential readings (120 - 143). Abingdon: Routledge.

Smith, K., MacKenzie, J. \& Meyers, R. (2014). Exploring the feasibility of international collaboration and relationship building through a virtual partnership scheme. International Journal for the Scholarship of Teaching and Learning, 8(1) article 7.

Sullivan, P.S.O., Stoddard, H.A. \& Kalishman, S. (2010). Collaborative research in medical education: A discussion of theory and practice. Medical Education, 1175-1184.

Trowler, P. (2004). Policy and Change: Academic development units and the Bologna Declaration. International Journal of Academic Development, 9(2), 195-200.

Walker, M. (2001). Reconstructing professionalism in university teaching: Teachers and learners in action. London: SRHE.

Wenger, E. (1998). Communities of practice: Learning, meaning and identity. Cambridge: Cambridge University Press.

\footnotetext{
i The figure in brackets refers to the unique identity of the team member. The biographical information of team members is contained in the appendix.
} 